\title{
Written assignments in distance learning and communication with learners as part of the role of the lecturer in the distant education
}

\author{
KoukousouriVasiliki, Andreas Karaoulanis MBAMScEngMScBEng \\ Hellenic Open University, Greece \\ Vaskoukou03@gmail.com \\ Cardiff University, United Kingdom \\ andrekaraoul@gmail.com
}

\begin{abstract}
In this paper the authors tried to underline the importance of distance learning as a means of distant education in the contemporary educational system. A literature review which explains why such a survey is very important in terms of this kind of modern learning was implemented.
\end{abstract}

A short revision of some very important past surveys around the topic of distance learning was carried out, especially in terms of the research questions and the methodological approach that past researchers used in order to dig deeper into the topic.

Finally, the results of such empirical researches were analyzed and some critical thoughts of the authors are presented.

\section{Indexing terms/ Keywords}

Distance learning; education; assignments; lecturer; methodological approach

\section{Academic Discipline And Sub- Disciplines}

Education; Research; Literary analysis

\section{SUBJECT CLASSIFICATION}

\section{Education}

\section{TYPE (METHOD/ APPROACH)}

\author{
Literary analysis; Research
}

\section{INTRODUCTION}

According to Lionarakis (2001, p.1), the most important issues in the application of distance learning are the design and production of educational / teaching material, which is the main lever of the educational process. Lionarakis continues that the teacher through a procedure of complementarity encourages the learning process through various forms of communication with the learners. How much a student is encouraged it depends on his personality and the diversity of educational problems. The synthetic expression "open and distance education seals the new educational dimension and methodology" (Lionarakis, 2001, p.2). An ally of distance learning is new technologies (Lionarakis, 2001, p.4). Lionarakis also emphasizes that in recent years, the Algex and the new technologies have been in constant communication, as LEXAR is defined as the education that teaches and energizes the student in self-action. Finally, he states (2001) that the distance is nullified and there is a variety of educational means.

This paper deals with the subject of written work in distance learning, examining the dimension of teachers' communication with the students as part of the role of the teacher-consultant in distance learning and especially in the writing of written papers. As Papadimitriou \&Lionarakis (2010) mentions, some skills are required by a teacher in the distance learning process that are different from the ones that a teacher in a conventional education system should possess. The need to develop a collaborative learning environment requires to play a different role than the traditional

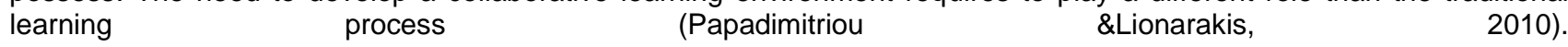

\section{IMPORTANCE AND NECESSITY OF THE SURVEY}

Research is a step-by-step process for gathering and analyzing information in order to increase understanding of a topic or issue. This means that we are conducting a survey to contribute to existing information on emerging issues (Creswell, 2016).

As in the present paper we will deal with the role of the teacher in distance learning, it is worth mentioning that according to Zygouris\&Mavroides (2011), the role of the counselor is particularly important as through the communication with the students it meets the needs of learners both at the level of learning support and at the emotional one. Communication can take many forms either by living, by e-mail or anything else. The needs of trainees are many and it is necessary to be satisfied. The professor - counselor is the most important constant to which the learners can get and rely on (Zygouris\&Mavroid, 2011).

The quality of the teacher-consultant communication with the trainees is decisive for the course of the students' studies (Lionarakis, 2001, pp. In lliadou, 2010). Iliadou (2010) emphasizes that the role of the teacher in distance learning differs from the role the teacher plays in traditional education because there is no classroom, the group of students consists of 
people from different ages and there is no immediate feedback. What makes distance learning to be different from the traditional - conventional teaching is the trainee's independence from the trainer (Moore, 1973, op. Ed., Iliadou, 2010).

Iliadou\&Anastasiadis (2010) highlight how important the writing of papers is. The student learns energetically (Lionarakis, 2001, cited in Iliadou\&Anastasiadis, 2010). Analytical comments are a form of a constructive dialogue and identify the positive points of work and its weaknesses.

Rowntree (1998) \& Race (1999) reported that only a few students are able to study based solely on their own strengths as they are not all familiar with this way of education. Keegan (2001, cited in Tzotzu\&Bijlaki, 2013) reports that students tend to abandon their studies at those distant institutions where the structures for reconnecting teaching activities are not restored to a satisfactory degree.

In distance learning, the transmitter and the receiver are in a different location and use communication means to exchange messages (Tompson, 1999, op. Cit., Sarakatsanou\&Vassala, 2011). Thus, new technologies contribute significantly to the realization of distance learning as they help to achieve a two-way communication and relieve the student from the need of physical presence in the educational process (Sarakatsanou\&Vassala, 2011).

OfraNirgal (2002) reminds us that a virtual learning environment allows students to be free from the time and place constraints. It also mentions the separation of modern and asynchronous learning (Beaudin, 1999, Ref., In Nirgal, 2002), as follows:

$\checkmark$ Modern learning: where we have the traditional model of learning with both teacher and student to be together and technology to be used targeted,

$\checkmark$ Asynchronous learning: where a teacher and a learner are not present at the same time as technology unites them.

According to Solomon (1996, cited in Nirgal, 2002), the role of the teacher is to be a diagnostic, promoter and mediator, to work with groups of students and to help them progress on their own.

The professor - counselor is like a "personal trainer" for those learning through computers (Sheidlinger, 1999, in Nirgal, 2002).Thus, in the present study we will analyze a series of empirical researches in which the authors, using quantitative qualitative approaches, investigated, among other things, the role of the teacher-consultant in distance learning. This dimension was chosen because it was considered particularly interesting and satisfying the curiosity and interest of the writer of this work, who is a teacher of secondary education, thus comes into contact and communicates with students on a daily basis.

Proper communication and feedback is of the greatest interest to the writer of this work and is a personal goal to be achieved.

\section{LITERATURE REVIEW}

\subsection{Theoretical reflection of reported empirical research}

According to Zygouris\&Mavroides (2011), who examined communication between a teacher and a trainee in distance learning, live, e-mail or anything else, the needs of the trainees are many and must be met.

The whole process of the distance learning method creates ancomplicated situation, as questions and practical problems cannot be solved directly by the "live" contact with the professor consultant. Teachers should have the appropriate skills to increase learner participation in the learning process and develop communication with trainees (Crossen, 2004, Wigforw, 1999, Manning, Cohen \& De Michieli, 2003, Kriakidis, 2007, pp. ref. to Zygouris\&Mavroides, 2011). As Boultonunderlined (2002, cited in Zygouris\&Mavroides, 2011), communication encourages the interaction, co-operation and teamwork among trainees. The role of the lecturer is to develop teaching methods that will enhance learning and communication, as well as use tools that will make learning more active, participative and constructive (Diaz \&Blazquez, 2005, Kiriakidis, 2007, cf. Zygouris\&Mavroides, 2011).

Studying the views of the students on the frequency, the subject, the ways and the quality of the communication is also investigated by the research of Iliadou\&Anastasiadis (2010). Writing is an important activity in which the student learns in an energetic way (Lionarakis, 2001, op. Ed., Iliadou\&Anastasiadis, 2010). The above research continues by investigating the role of the lecturer as a coordinator of the distance learning procedure, which provides psychological support to students and contributes to the increase of their self-confidence (Notaras, 2001). This study also examines the fact that there is no classroom, the group of students is uneven in age and there is no direct feedback (Iliadou\&Anastasiadis, 2010).

What makes distance learning different from traditional- conventional teaching is the trainee 's independence from the trainer (Moore, 1973, cited inlliadou\&Anastasiadis, 2010). The survey by Eliadou (2011) explores the subject of distance learning from a different perspective and examines the views of the teachers - advisors on the usefulness and quality of communication with students. The role of the counselor is multiple as she leads students to actively engage with the educational material and at the same time helps them to deepen his study and, of course, encourages them by supporting them psychologically (Eliadou, 2011).

The relationship between the teacher and the learner is bi-directional, so learning is promoted and therefore effective communication is necessary (Kokkos, 1998, op., In Eliadou, 2011). The trainee's needs are different so the adult trainer is 
required to have social skills to achieve effective communication and to properly manage crises and correct guidance (Courau, 2000, op., In Eliadou, 2011).

Peters (emphasis added in Iliadou, 2011) emphasizes that each educational organization should aim at autonomous and self-guided learning through educational material (Thorpe, 2001).

The objective ofthe empirical research of Sarakatsanou\&Vassila (2011), is the factors of development, context and impact of interpersonal-mediated student communication - consultant professor, in the students' learning process of the OR.

Swen (2011, cited in Sarakatsanou\&Vassala, 2011), states that in distance learning the high rate of interaction with the teacher helps students to be more satisfied with the education they offer.

Loizidou\&Chatzitheodoulou (2001, cited in Sarakatsanou\&Vassala, 2011) emphasizes that all forms of communication in distance learning are contributing to the emotional and academic support of the students. The "case study" focuses on the research by Tzotzou\&Bialaki (2013). They focused on the negative feelings of fear and insecurity that students feel about inadequate communication with the teacher. Although many students enjoy personalized learning, many feel uncertainty and anxiety (Tzotzu\&Bijlaki, 2013). Personalized learning in distance education refers to learning through action, is an individually and not a collective activity. It also focusedon the educational material provided, the support of the students, the role of the teacher (professor - counselor, interpersonal communication and the help provided by the new technologies) (Tzotzou\&Bijlaki, 2013).

OfraNirgal (2002) focuses on the use of computers by trainees, as people and information sources become available and readily accessible anywhere, anytime. Research continues, stressing that in recent years technology has developed special educational techniques for distance learning.

Thompson \& McGrath (1999, cited inNirgal, 2002) underlined that the most important factor which is affecting students in on line courses is the flexibility they offer. In all this, the question that arises has to do with the role of the counselor in virtual learning (Nirgal, 2002). Her role should be diagnostic and motivational, to mediate and work with groups of students who will help them to work and progress on their own (Solomon, 1996, op., Nirgal, 2002).

The study of Valais \&Andreadou stresses the fundamental principle of distance education: "continuous communication between the foundation and support of its students" (Holmberg, 2002, op.avap, Vassala\&Andreadou, 2009).

Vassala\&Andreadou continued that in the real communication (direct and indirect), it is of the utmost importance to create a two-way interaction, especially between students and the teacher-consultant and among students themselves. The communication is either face to face, or by e-mail or by the telephone. In real communication, the professor-consultant pursues specific goals using methods that promote active participation of the students and rely on experiential learning (Vassala\&Andreadou, 2009). The professor - counselor encourages trainees, supervises them, coordinates the whole procedure and, of course, evaluates written work (Vassala\&Andreadou, 2009).

\subsection{Research questions}

The research questions raised by Zygouris\&Mavroides (2011) are as follows:

1. What needs do students think their communication with the professor-consultant covers in a distance education program?

2.Which ways and forms of communication with the professor -consultant consider the students to be more effective?

3. How effective was the communication with the teacher- consultant in this training program?

4. How could this communication be improved in this program?

Iliadou\&Anastasiadis (2010) focused on:

1. What communication do students prefer and for what reasons?

2. What is the content / subject of communication?

3. If students evaluate their communication as successful.

4. How necessary and useful is the communication of students with teacher-consultant.

5. What features should the teacher- consultant have in order to be more effective?

For Vassala\&Andreadou important questions are:

1. Whether the support received by the graduates from the MSs was satisfactory.

2. What were their views on the communication developed with the teachers- consultants?

Although the survey by Eliadou (2011) deals with the communication from the teacher- consultant, the questions posed are again focused on "... content / subject of communication ... the way of communication preferred by the students .... and what are the characteristics that the teacher- consultant must have in order to be more effective ... and finally what is their attitude towards the dual role of the teacher- consultant ... "

Tzotzou\&Bijlaki (2013) are trying to find out:

1422 | P a g e

$\mathrm{Novem} \mathrm{ber} 2017$
D O I : $10.24297 /$ ijrem.v8i1.6432

w w w. cirwor|d.com 
1. To what extent students are familiar with personalized learning.

2. Whether individual learning meets the needs and aspirations of students.

They also make an effort to capture student suggestions to improve the implementation and promotion of personalized learning, while Sarakatsanou\&Vassala (2011) investigate:

1. Reasons for initiating, maintaining or interrupting communication with the teacher- consultant.

2. The factors that affect the frequency of communication.

3. What behavior on the part of the teacher- consultantstudents prefer?

4. What needs do they have to communicate with teacher- consultant?

5. If communication with the teacher- consultant contributes to learning.

\subsection{Methodological approach of listed empirical research}

In the empirical study of Zygouris\&Mavroidis (2011), the main purpose was to highlight the role of the teacher- consultant in distant education in the trainers' training program where a combination of quantitative and qualitative approach was used, i.e. a questionnaire and a semi-structured interview.

In the empirical research of Eliadou\&Anastasiades (2010), which took place during the academic year 2006-2007 and which concerned postgraduate students in the HOU(Hellenic Open University), the applied, descriptive - diagnostic research (quantitative) was used. More specifically, open and closed-ended questionnaires were distributed (which were processed with the SPSS statistical processing program).

In the empirical survey of lliadis (2011), which took place during the academic year 2006-2007 in HOU, a combination of quantitative and qualitative research was again followed, i.e. a questionnaire with both open and closed type questions (SPSS processing).

In the empirical study of Valais \&Andreados (2009), which was conducted during the academic year 2005-2006 to the graduates of the postgraduate program "Studies in Education", the methodological tools used were a questionnaire with open and closed type questions. Prior to the main survey, a preliminary study involving 15 people was preceded to check the clarity of the questions.

The empirical survey of Sarakatsanou\&Vassala (2011), which took place during the academic year 2006-2007, investigated the views of postgraduate students of the $\mathrm{HOU}$ in the "Studies in Education" \& "Adult Education" program. A qualitative methodological approach was followed using the semi-structured interview APPROACH.

In the Tzotzou\&Bijlaki (2013), an empirical research conducted during the academic year 2012-2013 concerning the exploration of the students' views of the postgraduate program "Studies in Education", using the quantitative research survey method (Cohen \&Manion, 1997) which is an exploratory research with an emphasis on discovery. A questionnaire with closed questions was shared, as well as open-ended questions that lead us to qualitative data analyzed on the basis of quality content analysis.

Finally, the Nirgal empirical research (2002) concerned 35 students of the Achva Academic College who participated in adistance learning program while the research was conducted during the academic year 1999-2000. Two open- ended questionnaires were used in this survey, which were sent by e-mail and several interviews.

\subsection{More important results of the empirical studies}

In Zygouris\&Mavroides (2011), the majority of trainees believe that trainers need to spend more time developing communication, stressing how strong this need is. This communication covers educational and emotional needs such as resolving questions about writing and preparing for the examinations (Zygouris\&Mavroidis, 2011). The research continues, emphasizing that the most important form of communication is the interpersonal one.

The survey by Eliadou\&Anastasiades (2010) states that directness, i.e. face-to-face communication, is the most effective. Second comes the by phone or by e-mail communication, while no one preferred the ordinary mail.

Although the survey of Iliadis (2011) takes into consideration the opinions of only 8 people, so the results do not allow us any generalizations, the teacher- consultant considers that the face to face communication is very important as there is interpersonal communication with the students. The researchcontinues that the writing of papers is more useful to students' study and is the most effective learning tool as well as an indirect way of communication and interaction between students (Eliadou, 2011).

In the Vassala\&Andreadou study (2009), the majority of graduates said that direct and indirect communication helped them solve the problems and encouraged them. The graduates agreed that their work was clearly commented on by the teacher- consultant, and that the comments were the basis of the students' feedback (Vassala\&Andreadou, 2009).

The Sarakatsanou\&Vassala (2011) research concludes that the preferred behavior of the teacher- consultant is to be available, friendly, responsive to the students' individual needs and to respond quickly to their messages. This means that the role of the teacher is to cover the educational and emotional needs of the students.

1423 | $\mathrm{P}$ a g e

November 2017
D O I : $10.24297 /$ ijrem.v8i1.6432 w w w. cirworld. co m 
The same conclusion is reached by the Tzotzou\&Bijlaki research (2013). It emphasizes the importance of interpersonal communication in the success of the learning process (Moore, 1996, Kokkos, 1999).

Finally, in the Nirgal empirical study (2002), the students responded to how important the guidance from the teacher was to the writing of the written work, as well as the psychological support provided to them. The form of this guidance can be in a virtual context, with interpersonal contact or a combination of both.

\section{CRITICAL EVALUATION OF BIBLIOGRAPHIC REVIEW}

Following the bibliographic review of seven empirical studies, which explored the role of the teacher- consultant through its communication with trainees, we conclude that the most important form of communication is the interpersonal one. The role of the teacher- consultant is double,to instruct and to help, emotionally and in practice. The teacher encourages, strengthens, evaluates, and advises (Konstantopoulou, 2001, cited inHatzistamatis, 2014). Telephone or emails are also very important as a direct way of communication with the teacher- consultant.The main subject of communication is to solve questions about written work or the need for relief from anxiety and insecurity. Simple mail is not preferred by trainees as it does not provide direct contact with the teacher.

Given that we have come to the conclusion that the most important form of communication in distance learning is the interpersonal one in the OSA, it is reasonable to ask whether distant education offers the same quality of education / knowledge as the traditional one. This question could be the subject of a future investigation.

\section{BIBLIOGRAPHY}

Creswell, J. (2016). Research in education. Athens, publishing group lon. Zygouris, F. \&Mavroidis, H. (2011). Teacher and learner communication in distance learning. Case study in the trainers training program of KEE.N. Open Education / Open Education International Journal. Volume 7 (\# 1). Retrieved on 12/10/2016 by: http://journal.openet.gr/index.php/openjournal/article/view/9769/9900 Vassala, P., Andreadou, D. (2009). Support from teachers, counselors and fellow students in distance learning. The views of the graduates of the postgraduate program "Education in Education" At: 5th International Conference in Open \& Distance Learning, November 2009, Athens - Greece. Retrieved on 12/10/2016 by: http://eproceedings.epublishing.ekt.gr/index.php/openedu/article/view/438

Eliadou, Ch. (2011). Contacting Teacher - Consultant and Students in Distance Learning: SEP Views of the EEEF65 of the EAP. International Open Education Journal / Open Education Journal. Article 7 (No. 1). Retrieved on 15/10/2016 by: http://journal.openet.gr/index.php/openjournal/article/view/9765/9896

Iliadou, Ch., \&Anastasiades, P. (2010). Contact of professor - counselor and students in distance learning: Students' views in the framework of the School of Economics. Open Education International Journal / Open Education Journal. Article 6 (No. 1, 2). Retrieved on 16/10/2016 from: http://journal.openet.gr/index.php/openjournal/article/view/9751/9884 Lionarakis, A. (2001). Open and Distance Diversity Education: Reflections on a qualitative teaching material design approach. In: Opinions and Reflections on Open and Distance Education, Lionarakis, A. (eds.), Athens: Propospos (2001). Retrieved on 16/10/2016 by: Elektra.teilar.gr/syncppt/qualityDesignofteachingMaterial.pdf Nir-Gal, O. (2002). Distance Learning: The role of the Teacher in a Virtual Learning Environment. Retrieved on 16/10/2016 from: $\quad$ http://www.achva.ac.il/sites/default/files/achvafiles/maof-book/8/2002-2pdf Papadimitriou, TH, \&Lionarakis, A. (2010). The role of the Professor-Counselor and the development of a support mechanism for distance learning. Open Education International Journal - Open and Distance Education. Vol.6 (No. 1 \& 2 ). Retrieved on 17/10/2016 by: http: //journal.openet,gr/index.php/openjournal/article/view/9754

Sarakatsanou, E., \&Vassala, P. (2011). Mediated Interpersonal Communication of Students and Teachers - Distance Learning Consultants. At: 6th International Conference on Open and Distance Learning, November 2011. Tom. 6 (No. 1A). Retrieved

on http://eproceedings.epublishing.ekt.gr/index.php/openedu/article/view/731/743 $17 / 10 / 2016$

by:

Tzotzou, M., \&Bialaki, N. (2013). Investigating Student Attitudes of the MSS "Learning in Education" for Distance Learning Personalized Learning of the EAP - A Case Study. International Open Education / Open Education Magazine. 9 (No. 1). Retrieved on 19/10/2016 http://ejournals.epublishing.ekt.gr/index.php/openjournal/article/view/9803/9930

Hatzistamatis, KB. (2014): Bibliographical Review and Critical Reading of Empirical Studies in the Forms of Communication Instructors - Teachers in the RU of the EAP. Retrieved on 21/10/2016 by: http://users.sch.gr/convichat/?cat=16

\section{AUTHORS}

KoukousouriVasiliki is studying her master's degree in Adult Education in Hellenic Open University. She is teaching in a public Greek school, while she is a very experienced teacher in the public and private Greek sector for more than 12 years. She acquired her bachelor degree in loannina Public University in Greece. She has a diverse vocational background as she is has a vast experience in several industries like academia, libraries, agricultural industry, hospitality, administration etc.

Andreas Karaoulanis MBAMScEngMScBEng has a master's degree in engineering from Aristotle university of Thessaloniki, a MBA in industrial management and economics from Blekinge Institute of Technology and a master's degree in decision support and risk analysis from Stockholm University. He was recently accepted as a PhD student in Cardiff University Business School, although he didn't enroll yet due to personal reasons. He is the author of several published papers in several international scientific blind peer review journals and he is peer reviewer in four international 
journals. He is teacher of English as foreign language for the last 4 years. He is experienced researcher while he has a strong background in several industries like banking, consulting, engineering, retail, education. 